\title{
PADRÃO DE FRATURAMENTOS DO MACICCO ALCALINO DE CANANÉIA, ESTADO DE SÃO PAULO: RELAÇÕES COM A TECTÔNICA MESOZÓICO-CENOZÓICA DO SUDESTE DO BRASIL
}

\author{
CLÁUDIO RICCOMINI
}

\begin{abstract}
FRACTURE PATTERN OF THE CANANÉIA ALKALINE MASSIF, STATE OF SAO PAULO AND ITS RELATIONSHIP TO MESOZOIC-CENOZOIC TECTONICS OF SOUTHEASTERN BRAZIL. The Cananéia Alkaline Massif is a small elliptical stock of Upper Cretaceous age located at the southern part of the State of São Paulo, Brazil. Brittle faults, joints and dykes which cut the massif are probably related with an Upper Cretaceous NE-SW extension and a Paleogene, probably Eocene, E-W transcurrence with NW-SE extension and NE-SW compression. Both tectonic phases have correlation with deformations along major regional tectonic features, the first with NE-SW extension along the NW-SE Guapiara Lineament of the Ponta Grossa Arch and the latter with the left-lateral E-W transcurrence along the ENE-WSW to E-W Proterozoic shear zones, reactivated during Early Tertiary times, and in part responsible for the origin and tectonic deformation of sedimentary basins included in the Continental Rift of Southeastern Brazil.
\end{abstract}

Keywords: brittle tectonics, Cananéia Alkaline Massif, Cenozoic continental rifting, São Paulo State, Brazil.

\begin{abstract}
RESUMO O Maciço Alcalino de Cananéia é um pequeno stock, de forma elfptica, localizado na cidade homônima, na porção sul do Estado de São Paulo. A análise do padrão de fraturamento do maciço indicou a provável vigência de duas fases de deformação, a primeira com extensão NE-SW, de idade cretácea superior, e a segunda, com caráter transcorrente sinistrai, de direção E-W, com compressão NE-SW e extensão NW-SE, de idade paleogênica, provavelmente eocênica. Estas duas fases apresentam relacões com deformacões ocorridas ao longo das feições tectônicas regionais, estando a primeira fase ligada à extensão ao longo do Alinhamento de Guapiara, que integra o Arco de Ponta Grossa, e a segunda com a transcorrência sinistrai, de direção E-W, que propiciou a reativação cenozóica de antigas zonas de cisalhamento de direções ENE-WSW a E-W de idade proterozóica, estas também responsáveis pela instalação e deformação das bacias que compõem o Rift Continental do Sudeste do Brasil.
\end{abstract}

Palavras-chaves: tectônica niptil, Maciço Alcalino de Cananéia, rift continental cenozóico, São Paulo, Brasil.

INTRODUÇÃO O Maciço Alcalino de Cananéia, localizado no município homônimo, sul do Estado de São Paulo (Fig. 1), é uma das inúmeras ocorrências de rochas alcalinas de idade mesozóica que pontilham a região situada entre o flanco sudeste da Bacia do Paraná e a linha de costa (v.g. Ulbrich \& Gomes 1981). Trata-se de um pequeno stock de forma elíptica, com eixo maior orientado segundo NE, e cerca de $0,45 \mathrm{~km}^{2}$ de área (Fig. 2). Sustenta uma pequena elevação com densa cobertura vegetal, o Morro de São João, com $137 \mathrm{~m}$ de altura máxima, que se destaca na paisagem em relação à planície vizinha, esta constituída por depósitos marinhos pleistocênicos da Formação Cananéia e sedimentos holocênicos dos manguezais (v.g. Suguio \& Tessler 1992).

Pioneiramente estudado por Freitas (1947), que nele reconheceu a presença de pulaskitos, nordmarkitos e solvsbergitos, o Maciço Alcalino de Cananéia foi datado pelo método K-Ar por Amaral et al. (1967), que obtiveram idades entre 80.7 e $84.4 \mathrm{Ma}$, com média em torno de $82 \mathrm{Ma}$, idades estas posteriormente recalculadas por Sonoki \& Garda (1988) para o intervalo entre 82.7 e $86.6 \mathrm{Ma}$, em função das novas constantes de decaimento, situando-o, portanto, no Cretáceo Superior.

$\mathrm{Na}$ vizinha Ilha Comprida, a pouco mais de $1 \mathrm{~km}$ do flanco sudeste da intrusão de Cananéia, ocorre outro pequeno corpo de rocha alcalina, sustentando a elevação designada de Morrete, a qual J. M. V. Coutinho (in Barcelos 1975) caracterizou petrograficamente como quartzo sienito (nordmarkito). Suguio et al (1987), através de perfilagens geofísicas, confirmaram a existência da chamada "Laje do Argolão", que constitui um fundo submerso rochoso, de provável natureza alcalina, contínuo no canal lagunar do Mar de Cananéia entre os morros de São João e Morrete, motivo pelo qual não se pode deixar de suspeitar que ambas as intrusões alcalinas sejam coetâneas e talvez interligadas em subsuperfície.

Após a sua colocação e resfriamento, o Maciço Alcalino de Cananéia comportou-se como um corpo rígido e relativamente homogêneo, do ponto de vista geomecânico. Parte das famílias de fraturas nele desenvolvidas podem estar ligadas ao seu resfriamento ou terem sido originadas durante seu movimento ascensional. Outras, entretanto, seriam pós-magmáticas, refletindo essencialmente a ação dos esforços tectônicos regionais.

Em levantamentos executados na região foram observadas algumas famílias de fraturas (falhas e juntas), além de diques de rochas alcalinas e ultrabásicas, que motivaram a elaboração de um estudo inicial destas estruturas. Este trabalho visa, portanto, a caracterização preliminar do padrão de fraturamentos do maciço e a verificação de sua correlação com a tectônica mesozóico-cenozóica da região sudeste do Brasil.

CONTEXTO GEOLÓGICO E TECTÔNICO REGIONAL A área em estudo encontra-se na junção de duas importantes feições tectônicas do sudeste do Brasil. Uma delas é o Arco de Ponta Grossa, de idade mesozóica, com direção noroeste, em relação ao qual o Maciço Alcalino de Cananéia encontra-se alojado no flanco sudoeste de um de 


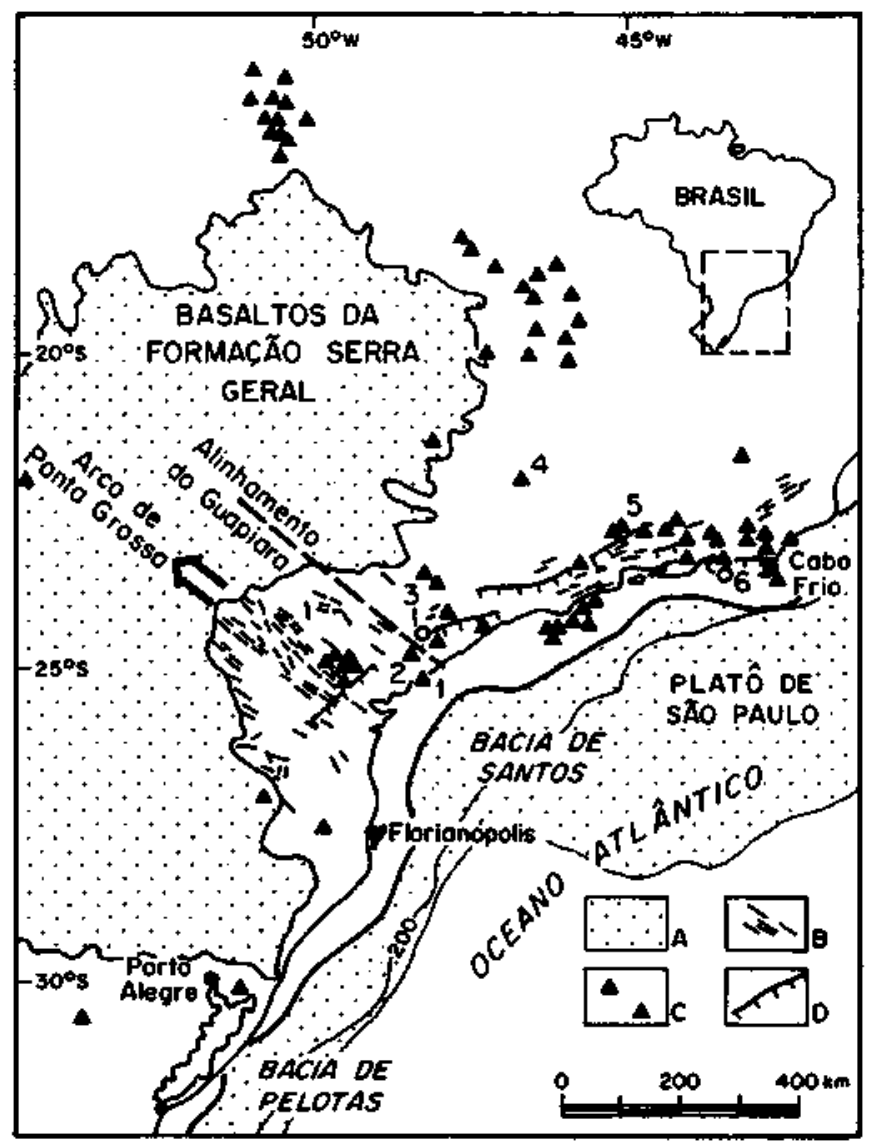

Figura 1 - O Maciço Alcalino de Cananéia (SP) no contexto geológico regional: 1 - Maciço Alcalino de Cananéia; 2 - Complexo Carbonatítico de Jacupiranga; 3 - Gráben de Sete Barras; 4 - Maciço Alcalino de Poços de Caldas; 5 - Maciço Alcalino de Itatiaia; 6 - Bacia de Itaboraí; $A$ - rochas basálticas (Bacia do Paraná); $B$ - diques de rochas básicas; $C$ - maciços de rochas alcalinas; $D$-falhas mestras cenozóicas do Rift Continental do Sudeste do Brasil Figure 1 - Regional geological setting of the Cananéia Alkaline Massif (São Paulo State, Brazil): 1 - Cananéia Alkaline Massif; 2 - Jacupiranga Carbonatite Complex; 3 - Sete Barras Gráben; 4 - Poços de Caldas Alkaline Massif; 5 - Itatiaia Alkaline Massif; 6 - Itaboraf Basin; A - basaltic rocks (Paraná Flood Volcanics); B - dykes of basic rocks; C - alkaline massifs; D - Cenozoic master faults of the Continental Rift of Southeastern Brazil

seus alinhamentos magnéticos mais importantes, o de Guapiara (Ferreira et al. 1981). Outra corresponde às zonas de cisalhamento pré-cambrianas, com reativações no Mesozóico-Cenozóico, controlando a formação, a sedimentação e a deformação das bacias tafrogênicas que compõem o Sistema de Rifts Continentais da Serra do Mar (Almeida 1976, Melo et al 1985) ou Rift Continental do Sudeste do Brasil (Riçcomini 1989).

E de se esperar, portanto, que o padrão de fraturamentos do Maciço Alcalino de Cananéia possa refletir o tectonismo associado à evolução destas feições.

PADRÃO DE FRATURAMENTOS Os levantamentos estruturais no Maciço Alcalino de Cananéia foram concentrados nas suas bordas, já que, rumo às porções mais centrais, além da dificuldade de acesso e carência de boas exposições, as rochas encontram-se aparentemente pouco fraturadas.

As estruturas estão bem expostas nas bordas noroeste, oeste e sudoeste do stock, onde foram observados

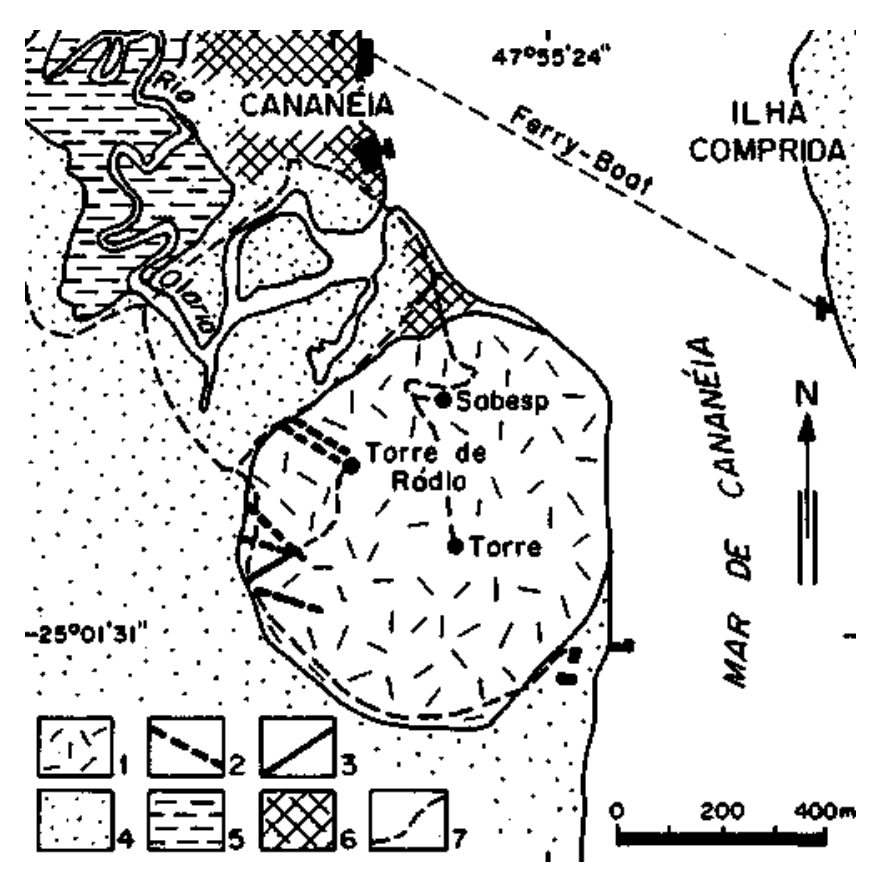

Figura 2 - Mapa geológico do Maciço Alcalino de Cananéia: 1 - sienito; 2 -diques de traquito; 3 - dique de lamprófiro; 4 - sedimentos marinhos pleistocênicos da Formação Cananéia; 5 - sedimentos holocênicos dos manguezais; 6 - área urbana de Cananéia; 7 - principais caminhos

Figure 2 - Geologic map of the Cananéia Alkaline Massif: 1 - syenite; 2 trachyte dykes; 3 - lamprophyre dyke; 4 - Pleistocene marine sediments of the Cananéia Formation; 5 - Holocene marshy sediments; 6 - urban area of the town of Cananéia; 7 - road, pathway

falhamentos de caráter rúptil, de rejeitos até decimétricos, fraturas com preenchimento de diques de traquito e lamprófiro, e juntas no maciço e nos diques de traquito.

Falhamentos no maciço Os falhamentos observados no maciço estão representados na Figura 3.

A família principal apresenta-se orientada segundo ENE, com mergulhos subverticais para SSE. Os deslocamentos observados no maciço e em diques de traquito e a posição das lineações de estrias de atrito indicam caráter normal com componente sinistrai a sinistrai com componente normal.

Secundariamente, ocorrem duas outras famílias, uma de falhamentos de direções WNW a NW, com mergulhos subverticais para SSW-SW, mostrando deslocamentos com componentes horizontais sinistrais de diques de traquito, para as quais, em função do mergulho das estrias de atrito, pode-se deduzir a existência de componentes reversas (aparentemente predominantes) e normais, e outra de direção NNE a NE, de falhas reversas com componentes dextrais.

Uma única falha mostrou direção N-S, com alto mergulho para $\mathrm{E}$, e caráter dextral normal, enquanto que, em uma única superfície de falha, de direção NNE, pode-se observar a superposição de estrias de atrito, indicando movimentação mais jovem de caráter dextral.

Diques Foram encontrados cinco diques subverticais de traquito, com espessuras variando entre 0,1 e $1,2 \mathrm{~m}$, apresentando direção preferencial segundo NW, e um dique de lamprófiro, com cerca de $8 \mathrm{~cm}$ de espessura, também subvertical e orientado segundo NE (Fig. 4). 


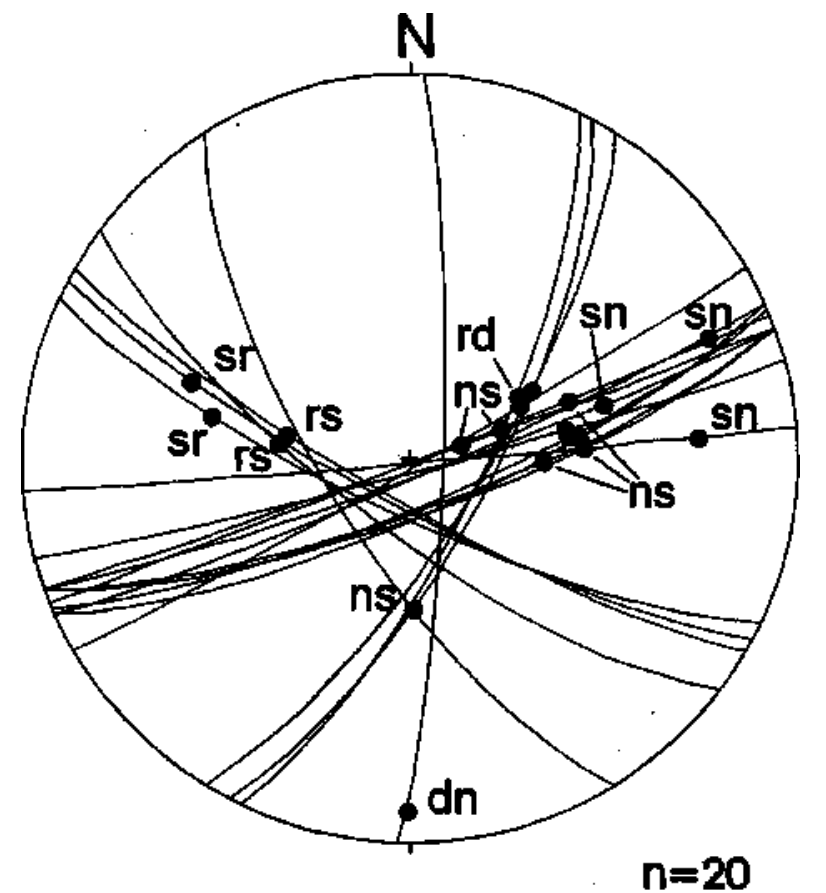

Figura 3 - Falhas (círculos máximos) e estrias (pontos) que seccionam o maciço, sendo o movimento relativo entre os blocos representado pelas letras ( $\mathrm{ns}$ - normal com componente sinistrai; sn - sinistrai com componente normal; rdreversa com componente dextral; rs - reversa com componente sinistrai; sr - sinistrai com componente reversa; $d n$ dextral com componente normal). Rede de SchmidtLambert, semi-esfera inferior

Figure 3 - Faults (great circles) and striae (dots) which cut the alkaline massif, showing the relative motion of the blocks (ns - normal with leftlateral component; sn - left-lateral with normal component; rd - reverse with right-lateral component; rs - reverse with left-lateral component; sr left-lateral with reverse component; dn - right-lateral with normal component). Equal-area projection, lower hemisphere

Juntas em diques Os diques de traquito apresentam juntas subverticais, não preenchidas, com espaçamento centimétrico a métrico, predominando o decimétrico, marcantemente orientadas segundo NE, em ângulos de $60 \mathrm{a} 75^{\circ} \mathrm{em}$ relação à direção dos diques (Fig. 4), algumas delas adentrando as rochas encaixantes.

Juntas no maciço As juntas cadastradas no maciço alcalino são subverticais, de espaçamento decimétrico a métrico, com predomínio deste último, definindo dois únicos agrupamentos, um principal, de direção WNW, e outro orientado segundo NNE (Fig. 5).

Relações entre as estruturas As relações de campo permitiram verificar que os diques de traquito de direção NW são as estruturas mais antigas, seguidas das juntas no maciço, estas em parte reativadas como falhas e provavelmente contemporâneas das juntas em diques de traquito e da intrusão de lamprófiro.

ANÁLISE DO PADRÃO DE FRATURAMENTOS Em função dos dados geofísicos disponíveis (Suguio et al. 1987), não há indicação de continuidade do Maciço Alcalino de Cananéia para nordeste e leste, sob o Mar de Cananéia. Assim, o corpo alcalino, como atualmente exposto, apresenta formato elíptico marcante, aparentemente desvinculado de controle litoestrutural pretérito, uma vez que a orientação de seu eixo maior é discordante das descontinuidades maiores do embasamento.

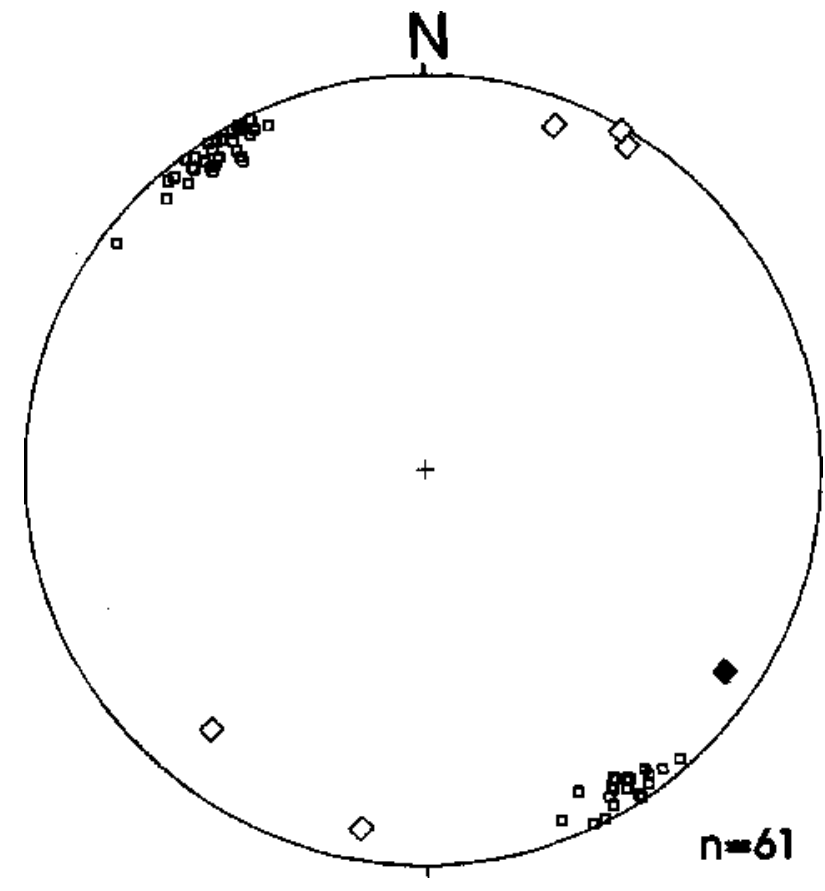

Figura 4 - Pólos das atitudes de diques de traquito (O), lamprófiro $(+)$ e de fraturas em diques de traquito $(D)$. Rede de Schmidt-Lambert, semi-esfera inferior Figure 4 - Poles to trachyte dykes (O), lamprophyre $(+)$ and fractures of trachyte dykes (D). Equal-area projection, lower hemisphere.

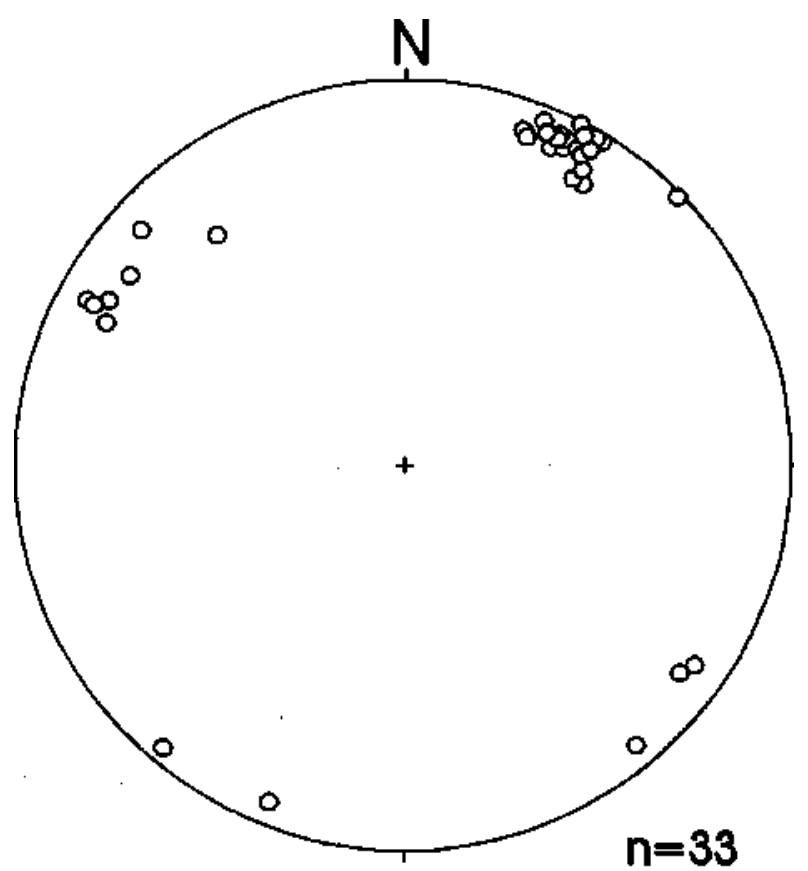

Figura 5 - Pólos de juntas no maciço. Rede de SchmidtLambert, semi-esfera inferior

Figure 5 - Poles to joints of the alkaline massif. Equal-area projection, lower hemisphere

Considerando-se a direção NW dos diques de traquito como sendo ortogonal à direção do esforço (stress) principal mínimo, 03, vigente durante a intrusão desses diques, verifica-se que ela corresponde exatamente ao eixo menor da elipse desenhada pelo contorno do Maciço Alcalino de 
Cananéia, o que permitiria situar o esforço horizontal máximo, aHmax (sendo aHmax $\geq \sigma \mathrm{l}$ ), nesta direção.

A conformação do maciço poderia ser considerada como a seção horizontal do elipsóide de deformação (strain), permitindo a estimativa da taxa de extensão mínima em $6,7 \%$, em função das dimensões dos seus eixos e assumindo-se que o corpo possuia originalmente seção horizontal circular.

Assim, ao menos durante a fase tardia de colocação do maciço, à época da intrusão dos diques de traquito que o seccionam, teria ocorrido extensão segundo a direção NE-SW.

A orientação destes diques é também consistente com a da "Laje do Argolão", submersa, que liga o Maciço Alcalino de Cananéia e o Morrete, o que faz supor tratar-se esta também de um dique de traquito.

A principal família de juntas observadas no maciço é concordante com a orientação dos diques de traquito, o que permite supor que possa ter sido, ao menos em parte, gerada sob as condições de esforços acima descritas. A família secundária é concordante com falhamentos de direção NNENE e com a direção do dique de lamprófiro. Algumas juntas no maciço devem corresponder a falhas onde não foi possível o estabelecimento de rejeitos nem a observação de lineações de estrias de atrito.

Analisando-se as populações de falhas e respectivas estrias de atrito, pelo método gráfico de Angelier \& Mechler (1977), pode-se verificar que todas elas mostram consistente direção de encurtamento máximo (tensão máxima, ai) segundo NE-SW, horizontal. Com certa dispersão, a extensão máxima (tensão mínima, $\sigma 3$ ) encontra-se em posição variável, desde subvertical até horizontal, segundo a direção NW-SE (Figura 6).

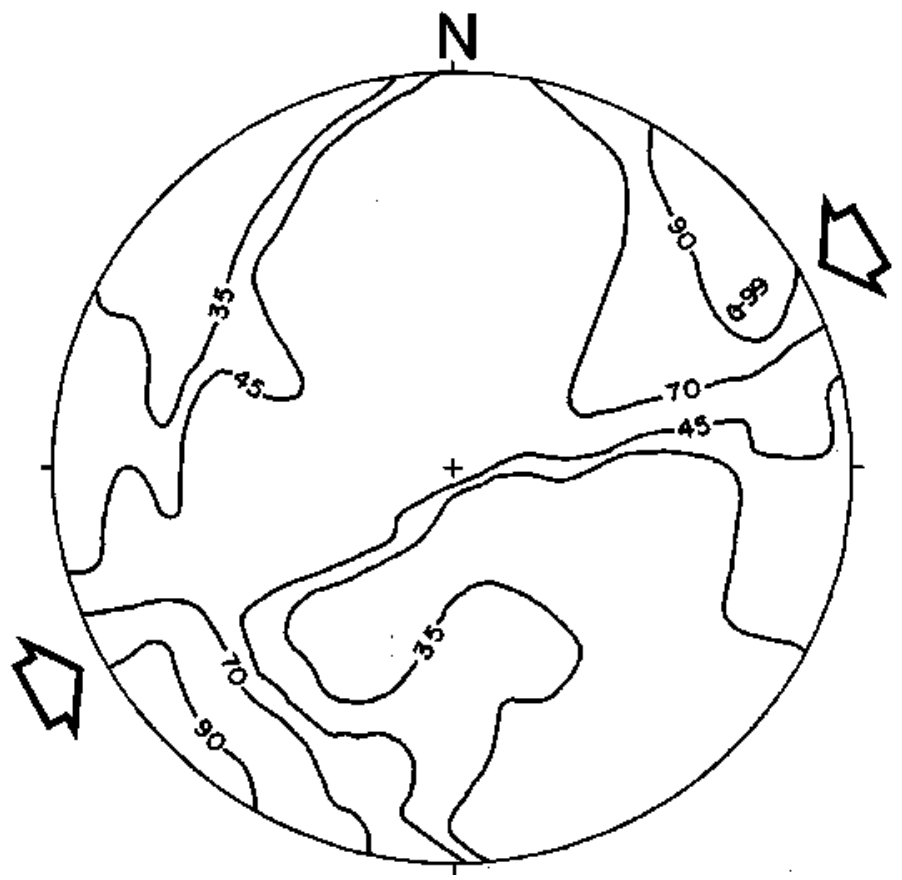

Figura 6 - Resultado da aplicação do método gráfico de Angelier \& Mechler(1977) à população de falhas da Figura 3. As isolinhas de porcentagem mais elevada delimitam os campos de maior probabilidade de conter o eixos de tensão máxima (d) e as de menor valor o eixo de tensão mínima $(\sigma 3)$. As setas indicam a direção de encurtamento. Rede de Schmidt-Lambert, semi-esfera inferior

Figure 6 - Result of application of the method of Angelier \& Mechler (1977) for the fault population of Figure 3. The higher and lower isoline values (in \%) indicate, respectively, the higher and lower probability field for the maximum (ol) and minimum (a3) stress axes. Arrows indicate the shortening direction. Equal-area projection, lower hemisphere
Em princípio, tal disposição de $\sigma 3$ permitiria contemplar mecanismos variando de empurrão $(\sigma 1$ horizontal e $\sigma 3$ subvertical) a transcorrente ( $\sigma 1$ e $\sigma 3$ horizontais). Levandose em conta o caráter subvertical das falhas e juntas no maciço, o regime tectônico exigiria $\sigma 2$ vertical, o que leva a considerar como mais provável que o mecanismo, no caso em estudo, seja transcorrente. O caráter oblíquo dos rejeitos das falhas estudadas seria explicado por reativações de descontinuidades anteriormente formadas.

$\mathrm{O}$ conjunto de falhas analisado indicaria a vigência de regime transcorrente sinistrai, com binário orientado segundo E-W. Neste modelo, as falhas de direção ENE, WNW-NW, NNE-NE e N-S podem corresponder, respectivamente, a fraturas dos tipos R, P, R' e X de Riedel (v.g. Sadowski 1984). Na bissetriz aguda entre R e R', ou seja na direção NE-ENE, ocorre a compressão máxima, sendo geradas fraturas $\mathrm{T}$, nesta direção. Esta seria talvez a explicação mais plausível para a origem das juntas que seccionam os diques, que apresentam atitudes perfeitamente concordantes com a deste modelo teórico, e discrepantes do padrão usualmente exibido por juntas de resfriamento. A concentração das juntas nos diques poderia ser explicada pela diferença de competência destas rochas - de granulação extremamente fina, homogênea e matriz parcialmente vítrea - em relação às encaixantes.

Como antes mencionado, a existência de superposição de movimentos, em um mesmo plano de falha, poderia indicar a resposta do maciço a nova mudança no campo de esforços, cuja caracterização dependeria de maior volume de dados.

Na Figura 7 é apresentada a seqüência de eventos ora proposta.

Deve ser apontada ainda a semelhança do padrão de fraturamentos do Maciço Alcalino de Cananéia com aquele verificado nos Granitóides Mandira, situados a pouco me-
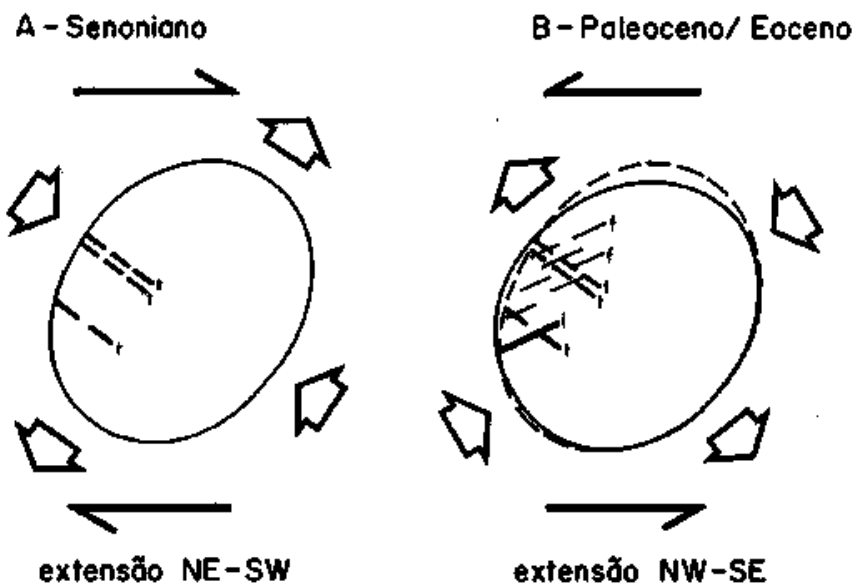

Figura 7 -Modelo tectônico proposto para o Maciço Alcalino de Cananéia: $A$ - extensão NE-SW, com a colocação dos diques de traquito ( $t$ ) de direção $N W-S E ; B$ - extensão $N W$ $S E$ e compressão $N E-S W$, com a colocação de dique de lamprófiro (l) e fraturamento nos diques de traquito $(f)$. Em $B$, a elipse tracejada representaria o contorno do maciço na fase $A$, enquanto que a elipse em linha contínua corresponderia à sua forma atual, com extensão finita de cerca de $6,7 \%$

Figure 7 - Proposed tectonic model for the Cananéia Alkaline Massif: A NE-SW extension and emplacement of NW-SE trachyte dykes (t); B NW-SE extension and NE-SW compression, emplacement of lamprophyre dyke (1) and development of fractures (f) in trachyte dykes. In B the ellipse and dashed ellipse represent, respectively, the present shape (with an estimate of finite extension of $6.7 \%$ ) and the probable shape of the massif during phase $\mathrm{A}$ 
nos de $10 \mathrm{~km}$ ao norte de Cananéia (Riccomini \& Crósta 1988), sugerindo a provável existência de movimentações cretáceas e terciárias nestes granitóides eopaleozóicos.

RELAÇÕES COM A TECTÔNICA REGIONAL A atividade tectônica mesozóica, relacionada ao Arco de Ponta Grossa e seus alinhamentos magnéticos, entre os quais o de Guapiara, ocorreu no Cretáceo Inferior (Renne et al. 1992, Turner et al. 1994). Nesse período, o Alinhamento de Guapiara comportou-se como uma zona de fissura com cerca de $600 \mathrm{~km}$ de extensão e 20 a $60 \mathrm{~km}$ de largura, onde ocorreu a intrusão de volume descomunal de magma basáltico, sob a forma de diques, tendo esta porção crustal experimentado afinamento de $14 \%$, com ascensão máxima do manto de 5 $\mathrm{km}$, e extensão mínima da ordem de $18 \%$, já que o fraturamento rúptil teria sido precedido em certo grau por extensão dúctil, esta não estimada (Ferreira et al. 1989). De qualquer forma, estes valores de extensão e afinamento obtidos são da mesma ordem de grandeza e sugestivos da vigência de regime de cisalhamento praticamente puro, com $\sigma 3$ horizontal, orientado segundo NE-SW.

A extensão NE-SW constatada no Maciço Alcalino de Cananéia seria coerente com aquela verificada no Alinhamento do Guapiara, o que poderia, a princípio, sugerir a permanência do mesmo regime de esforços até o Cretáceo Superior. Entretanto, o modelo estrutural estabelecido por Hasui et al. (1992), para a vizinha Mina de Carbonatito de Jacupiranga, contemplaria deformação resultante da ação de um binário dextral, de orientação aproximada E-W, com ai de direção NNW, a3 ENE eo2 vertical. Considerando-se a idade neocomiana do Maciço de Jacupiranga (131 $\pm 3 \mathrm{Ma}$, segundo Amaral 1978 e Roden et al. 1985), imediatamente posterior às intrusões de rochas básicas, a região teria passado para regime transcorrente dextral, mantida a direção NE-SW de extensão, mas com permutação entre $\sigma 1 \mathrm{e}$ $\sigma 2$, aparentemente vigente até a colocação do Maciço de Cananéia e dos diques de traquito que o seccionam (Riccomini 1995).

Em condições francamente rúpteis, após a colocação e resfriamento do maciço, são registradas juntas e falhas, estas últimas relacionadas à transcorrência sinistrai, com binário orientado segundo E-W, com compressão NE-SW e extensão NW-SE, propiciando a colocação do dique de lamprófiro e a geração de juntas nos diques de traquito.

Este novo regime de esforços promoveria a reativação de estruturas antigas do embasamento, em especial as zonas de cisalhamento de direção NE a ENE. Seria compatível com a direção de extensão deduzida para a fase de instalação das bacias integrantes do Rift Continental do Sudeste do Brasil (v.g. Riccomini 1989), incluindo-se o vizinho Gráben de Sete Barras (Melo 1990), ou ainda com as direções de encurtamento e extensão relacionadas à primeira fase tectônica deformadora das bacias desse rift (Riccomini 1989), bem registrada também nos maciços alcalinos de Itatiaia
(Riccomini et al. 1989), do Cretáceo Superior, e de Poços de Caldas (Etchebehere et al 1992), do Cretáceo a Paleógeno (idades originalmente determinadas por Amaral et al. 1967, posteriormente recalculadas para o intervalo de 89,3-54,3 Ma por Sonoki \& Garda 1988).

Na Bacia de Itaboraí, RJ, dique de rocha ultrabásica de direção NE-SW, intrusive em calcários paleocênicos, foi datado do Eoceno (Riccomini \& Rodrigues-Francisco 1992), fornecendo portanto uma referência absoluta de idade para esta extensão NW-SE.

Dessa forma, as deformações na área estariam inicialmente relacionadas à tectônica essencialmente extensional de um presumível domo térmico que evoluiu para junção tríplice, da qual o Arco de Ponta Grossa seria o ramo abortado. Posteriormente, com a ruptura do Gondwana e o início da deriva continental, ocorreria alternância no regime de esforços, que pode ser explicada pela migração da Placa Sul Americana no rumo oeste, combinada com as taxas de encurtamento e extensão, respectivamente nos seus flancos oeste, com a Placa de Nazca, e leste, na Dorsal Meso-Atlântica, conforme modelo proposto por Riccomini (1989).

CONCLUSÕES O padrão de fraturamentos do Maciço Alcalino de Cananéia registra parte da evolução dos regimes de esforços atuantes no sudeste brasileiro durante o Mesozóico e o Cenozóico.

No Cretáceo Superior, durante os estágios finais de colocação do maciço, acompanhando a intrusão de diques de traquito, esta porção crustal respondia aos esforços trativos, de direção NE-SW, que provavelmente perduravam na região do Arco de Ponta Grossa desde o Cretáceo Inferior (Neocomiano).

Provavelmente no Paleógeno (Eoceno) ocorre alternância para regime transcorrente sinistrai, com compressão NESW e extensão NW-SE, com a colocação de diques de lamprófiro, provavelmente relacionado com a primeira fase de atividade tectônica deformadora das bacias do Rift Continental do Sudeste do Brasil.

A exemplo dos estudos realizados nos maciços alcalinos de Itatiaia (Riccomini et al. 1989) e de Poços de Caldas (Etchebehere et al 1992), além da Mina de Carbonatito de Jacupiranga (Hasui et al 1992), a análise ora efetuada demonstrou novamente que os maciços alcalinos, pela natureza relativamente homogênea e comportamento geomecânico de suas rochas, constituem sítios favoráveis ao estudo da tectônica rúptil mesozóico-cenozóica do sudeste brasileiro.

Agradecimentos $\mathrm{O}$ autor externa seus agradecimentos aos Profs. Drs. Yociteru Hasui (IGCE-UNESP), Allaoua Saadi (CPMTC-UFMG) e Georg R. Sadowski (IG-USP) pela leitura crítica do manuscrito e inúmeras sugestões apresentadas.

\section{REFERENCIAS BIBLIOGRÁFICAS}

ALMEIDA, F.F.M. 1976. The system of continental rifts bordering the Santos Basin, Brazil. An. Acad. bras. Ci., 48(suplemento): 15-26.

AMARAL G 1978 Potassium-argon age studies on the Jacupiranga Alkaline District, State of São Paulo, Brazil. In: INTERNATIONAL SYMPOSIUM ON CARBONATITES, 1 . Pocos de Caldas, MG, Brazil, 1976. Proceedings... Poços de Caldas, MME/DNPM, p. 295-302.

AMARAL, G.; BUSHEE, J.; CORDANI, U.G.; KAWASHITA, K. REYNOLDS, J.H. 1967. Potassium-argon ages of alkaline rocks from southern Brazil. Geoch. Cosmoch. Acta, 31:117-142.

ANGELIER, J. \& MECHLER, P. 1977. Sur une méthode graphique de recherche dês contraintes principales egalement unusable en tectonique et en seismologie: la méthode dês dièdres droits. Bull. Soe. Géol France 7:1309-1318, Paris.

BARCELOS, J.H. 1975. Sedimentação e subambientes deposicionais da Ilha Comprida, São Paulo. São Paulo, 155p. (Dissertação de mes- trado apresentada ao Instituto de Geociências da Universidade de São Paulo).

ETCHEBEHERE， M.L.C.; HASUI. Y; MAGALHÃES, F.S. FRANGIPANI, A. 1992. Análise estrutural aplicada à prospecção de fontes termais no Planalto de Poços de Caldas (SP/MG), In: HASUI, Y. \& MIOTO, J.A., coords., Geologia Estrutural Aplicada. São Paulo, ABGE/VOTORANTIM, p. 439-459.

FERREIRA, F.J.F : MORAES, R.A.V; FERRARI M.P ; VIANNA, R.B. 1981. Contribuição ao estudo do Alinhamento Estrutural de Guapiara. In: SIMPÓSIO REGIONAL DE GEOLOGIA, 3, Curitiba, 1981. Atas... Curitiba. SBG. v. 1. p. 226-240.

FERREIRA, F JF • MONMA, R · CAMPANHA, G. A.C; GALLI. V.L. 1989. An estimate of the degree of crustal extension and thinning associated with the Guapiara Lineament based on aeromagnetic modelling. Boi. IG-USP, Série Científica, 20:69-70. 
FREITAS, R.O. 1947. Eruptivas alcalinas de Cananéia, Estado de São Paulo. Boletim da Faculdade de Filosofia, Ciências e Letras da Universidade de São Paulo, Geologia, 4:35p.

HASUI, Y ; MAGALHÃES, F S · COPPEDE JR, A ; MARGUTTI, R.L. 1992. Mina de Carbonatito de Jacupiranga (SP): permeabilidade do maciço avaliada pelo modelo geoestrutural, In: HASUI, Y. \& MIQTO, J.A., coords.. Geologia Estrutural Aplicada. São Paulo, ABGE/ VOTORANTIM, p. 383-398.

MELO, M.S. 1990. A Formação Paríqüera-Açu e depósitos relacionados: sedimentação, tectônica e geomorfogênese. São Paulo, 21 Ip. (Dissertação de mestrado apresentada ao Instituto de Geociências da Universidade de São Paulo).

MELO, M.S.; RICCOMINI, C.; HASUI, Y; ALMEIDA, F.F.M COIMBRA, A.M. 1985. Geologia e evolução do sistema de bacias tafrogênicas continentais do sudeste do Brasil. Rev. Bras, Geoc., 15:193-201.

RENNE, P.R.; ERNESTO, M.; PACCA, I.G.; COE, R.S.; GLEN, J.M PREVOT, M. PERRIN, M. 1992. The age of Paraná flood volcanism, rifting of Gondwanaland, and the Jurassic-Cretaceous boundary. Science, 258:975-979.

RICCOMINI, C. 1989. O Rift Continental do Sudeste do Brasil. São Paulo, 256p. (Tese de doutoramento apresentada ao Instituto de Geociências da Universidade de São Paulo).

RICCOMINI, C. 1995. Tectonismo gerador e deformador dos depósitos sedimentares pós-gonvânicos da porção centra-oriental do Estado de São Paulo e áreas vizinhas. São Paulo, 1OOp. (Tese de livredocência apresentada ao Instituto de Geociências da Universidade de São Paulo).

RICCOMINI, C. \& CRÓSTA, A.P. 1988. Análise preliminar de lineamentos em produtos de sensores remotos aplicada à prospecção mineral na área dos Granitóides Mandira, SP. Boi. IG-USP, Série Cientifica, 19:23-37.

RICCOMINI, C. \& RODRIGUES-FRANCISCO, B.H. 1992. Idade potássio-argônio do derrame de ankaramito da Bacia de Itaboraf, Rio de Janeiro, Brasil: implicações tectônicas. In: CONGRESSO BRASILEIRO DE GEOLOGIA, 37, São Paulo, 1992. Boletim de Resumos Expandidos... São Paulo, SBG, v. 2, p. 469-470.
RICCOMINI, C.; NEUMANN, R.; MATOS, S.L.F. 1989. Convergent strike-slip faulting in passive continental margin, southeastern Brazil. In: INTERNATIONAL GEOLOGICAL CONGRESS, 28, Washington, DC, USA, 1989. Abstracts... Washington, International Union of Geological Sciences, v. 2, p. 694

RODEN, M.F.; MURTHY, V.R.; GASPAR, J.C. 1985. Sr and Nd isotopic composition of the Jacupiranga carbonatite. /. Geol., 93:212-220.

SADOWSKI, G.R. 1984. Estado da arte do tema: geologia estrutural de grandes falhamentos. In: CONGRESSO BRASILEIRO DE GEOLOGIA, 33, Rio de Janeiro, 1984. Anais... SBG, Rio de Janeiro, v. 4, p. $1767-1793$.

SONOKI, I.K. \& GARDA, G.M. 1988. Idades K-Ar de rochas alcalinas do Brasil meridional e Paraguai oriental: compilação e adaptação às novas constantes de decaimento. Boi. IG-USP, Série Científica, 19:63-85.

SUGUIO, K. \& TESSLER, M.G. 1992. Depósitos quaternários da Planície Costeira de Cananéia-Iguape (SP). In: CONGRESSO BRASILEIRO DE GEOLOGIA, 37, São Paulo, 1992. Roteiro de excursão... SBG, São Paulo, v. 1, 31 p.

SUGUIO, K.; TESSLER, M.G; FURTADO, V. V.; ESTEVES, C.A.; SOUZA, L.A.P. 1987. Perfilagens geoffsicas e sedimentação na área submersa entre Cananéia e Barra de Cananéia (SP). In: SIMPÓSIO SOBRE ECOSSISTEMAS DA COSTA SUL E SUDESTE BRASILEIRA, 1, Cananéia, 1987. Síntese dos conhecimentos... Cananéia, Academia de Ciências do Estado de São Paulo, v. 2, p. 234-241 (Publicação ACIESP n» 54-11).

TURNER, S.; REGELOUS, M.; KELLEY, S.; HAWKESWORTH, S.; MANTOVANI, M. 1994. Magmatism and continental break-up in the South Atlantic: high precision ${ }^{40} \mathrm{Ar}-{ }^{39} \mathrm{Ar}$ geochronology. Earth Planet. Sci. Lett., 124:333-348.

ULBRICH, H.H.G.J. \& GOMES, C.B. 1981. Alkaline rocks from continental Brazil. Earth Science Reviews, 17:135-154.

MANUSCRITO A834

Recebido em 12 de abril de 1995 Revisão do autor em 10 de março de 1996 Revisão aceita em 20 de março de 1996 